\title{
Significant improvement of apolipoprotein B-containing lipoprotein metabolism by insulin treatment in patients with non-insulin-dependent diabetes mellitus
}

\author{
L. Duvillard, F. Pont, E. Florentin, P. Gambert, B. Vergès
}

INSERM U 498, Metabolism of human lipoproteins and vascular interactions, Faculty of Medicine, 21033 Dijon, France

\section{Abstract}

Aims/hypothesis. Patients with Type II (non-insulindependent) diabetes mellitus have multiple abnormalities in apolipoprotein B (apoB)-containing lipoprotein metabolism. These abnormalities are likely to play an important part in the development of premature atherogenesis in these patients. This stable isotope kinetic experiment was designed to study the effect of insulin therapy on apoB metabolism in poorly controlled Type II diabetic patients.

Methods. Using L-[1- $\left.-{ }^{13} \mathrm{C}\right]$ leucine, we studied apoB metabolism in five control subjects without insulin resistance and in six poorly controlled Type II diabetic patients before and 2 months after the introduction of insulin therapy.

Results. Insulin treatment induced a decrease of very low density lipoprotein apoB plasma concentration $\left[121 \pm 42\right.$ vs $158 \pm 91 \mathrm{mg} \cdot 1^{-1}, p<0.05$ (control subjects: $48 \pm 20$ )], related to an increased catabolism of very low density lipoprotein towards intermediate density lipoprotein or low density lipoprotein $\left[0.20 \pm 0.08\right.$ vs $0.14 \pm 0.07 \mathrm{pool} \cdot \mathrm{h}^{-1}, p<0.05$ (control subjects: $0.36 \pm 0.10)]$. On the other hand, insulin treatment induced an acceleration of intermediate density lipoprotein apoB turn-over without changing its plasma concentration [ $77 \pm 39$ vs $61 \pm 18 \mathrm{mg} \cdot 1^{-1}$, (control subjects: $17 \pm 3$ )], by increasing both its production rate $\left[22.6 \pm 9.2\right.$ vs $18.2 \pm 9.6 \mathrm{mg} \cdot \mathrm{l}^{-1} \cdot \mathrm{h}^{-1}$, $p<0.05$ (control subjects: $18.4 \pm 3.2$ )] and its catabolic rate towards low density lipoprotein $[0.34 \pm 0.22$ vs $0.22 \pm 0.16$ pool $\cdot \mathrm{h}^{-1}, \quad p<0.05$ (control subjects: $1.02 \pm 0.13)]$. Likewise, insulin treatment increased low density lipoprotein apoB production rate $\left[20.2 \pm 7.4\right.$ vs $16.9 \pm 7.7 \mathrm{mg} \cdot \mathrm{l}^{-1} \cdot \mathrm{h}^{-1}, p<0.05$ (control subjects: $16.9 \pm 2.3$ )] and restored a normal low density lipoprotein apoB fractional catabolic rate $\left[0.022 \pm 0.004\right.$ vs $0.018 \pm 0.004 \mathrm{pool} \cdot \mathrm{h}^{-1}, p<0.05$ (control subjects: $0.025 \pm 0.004$ )], resulting in a constant low density lipoprotein apoB plasma concentration $\left[965 \pm 485 \mathrm{vs} 984 \pm 558 \mathrm{mg} \cdot \mathrm{l}^{-1}\right.$ (control subjects: $699 \pm 106)]$.

Conclusion/interpretation. Insulin treatment in Type II diabetes induces profound metabolic modifications of lipoprotein, resulting in significant decrease of the intravascular residence time of very low density lipoprotein, intermediate density lipoprotein and low density lipoprotein particles. This is likely to make these particles less harmful. [Diabetologia (2000) 43: 27-35]

Keywords Non-insulin-dependent diabetes mellitus, insulin, apolipoprotein B, stable isotope, kinetic study, leucine.
Received: 31 May 1999 and in final revised form: 6 August 1999

Corresponding author: L. Duvillard, Laboratoire de Biochimie des Lipoprotéines, Hôpital du Bocage, BP 1542, 21034 Dijon, France

Abbreviations: Apo, Apolipoprotein; FCR, fractional catabolic rate; $\mathrm{GC} / \mathrm{C} / \mathrm{IRMS}$, gas chromatography/combustion/isotope ratio mass spectrometry; PR, production rate; SSPG, steady state plasma glucose; TG, triglyceride; VLDL, very low density lipoprotein; LDL, low density lipoprotein; IDL, intermediate density lipoprotein.
Cardiovascular diseases are the most common complications observed in Type II (non-insulin-dependent) diabetes mellitus [1]. The multiple abnormalities in lipoprotein metabolism frequently associated with Type II diabetes play an important part in the premature development of atherosclerosis in Type II diabetic patients. They generally have an increased plasma concentration of very low density lipoprotein (VLDL) particles that has been linked both to an increased synthetic rate and a decreased catabolic rate 
of VLDL apolipoprotein $\mathrm{B}(\mathrm{apoB})$ and triglycerides [2-6]. Although the low density lipoprotein (LDL) cholesterol concentration is generally normal or only moderately raised in Type II diabetic patients, LDL, apoB metabolism is impaired. In severe or moderately severe Type II diabetes, the LDL apoB production rate has been reported to be either normal or increased, whereas LDL apoB catabolic rate was either decreased or normal $[5,7]$.

Patients with poor glycaemic control despite oral antidiabetic agents and diet are treated by insulin which generally induces beneficial effects on the Type II diabetic dyslipidaemia. Hypertriglyceridaemia is improved by insulin treatment, leading to the reduction of VLDL and intermediate density lipoprotein (IDL) particle number and to the diminished triglyceride content of VLDL. This suggests that VLDL and IDL apoB metabolism are modified by insulin treatment. On the other hand, LDL cholesterol concentration is frequently not affected by insulin therapy $[8,9]$. Nevertheless, it does not exclude LDL apoB metabolism modifications induced by insulin therapy.

The steps of apoB metabolism influenced by longterm insulin treatment are not precisely known. So far, very few kinetic studies have been done to analyse the effect of insulin treatment on ApoB metabolism in Type II diabetes. The effect of insulin therapy in Type II diabetic patients has been studied using radio-isotopes [10], but the modifications of apoBcontaining lipoprotein metabolism shown in the studied patients before the introduction of insulin treatment were not necessarily representative of the abnormalities observed in all Type II diabetic subjects. Indeed, these studied patients had no increase of total VLDL apoB production and had a normal LDL apoB catabolic rate.

Usually, Type II diabetic patients become candidates for insulin treatment because diabetes is poorly controlled and there are strong apoB metabolism abnormalities. Thus, to analyse precisely the effect of insulin treatment on apoB-containing lipoprotein metabolism in Type II diabetes, we did the first in vivo stable isotope kinetic study on the whole VLDL $\rightarrow$ IDL $\rightarrow$ LDL cascade in poorly controlled Type II diabetic patients before and 2 months after the introduction of insulin therapy.

\section{Subjects and methods}

Subjects. We studied six Type II diabetic patients and five healthy normolipidaemic subjects with normal glucose tolerance. All subjects underwent physical examination and laboratory tests for exclusion of hepatic, renal and thyroid abnormalities. Control subjects did not take any medication. At their entry in the study, Type II diabetic patients were treated with oral antidiabetic drugs [both sulphonylureas (glibenclamide $15 \mathrm{mg} /$ day) and metformin $(2550 \mathrm{mg} /$ day) in all patients].
They were not taking any drugs that could affect lipid metabolism. Insulin treatment was started for Type II diabetic patients after the first kinetic experiment. It consisted of two daily injections of intermediate acting human insulin at a dose of 0.26 to $1 \mathrm{U} \cdot \mathrm{kg}^{-1} \cdot \mathrm{day}^{-1}$. Physical and biochemical characteristics of control and Type II diabetic subjects are shown in Table 1. The experimental protocol was approved by the ethics committee of the Dijon University Hospital, and written informed consent was obtained from each subject before the study.

Experimental protocol. Two kinetic studies were done in each Type II diabetic patient: the first before the introduction of insulin therapy and the second 2 months later.

The day before the kinetic experiment, insulin resistance was estimated in Type II diabetic subjects by the insulin suppressive test [11]. Briefly, insulin-stimulated glucose uptake was estimated by measuring the steady state plasma glucose (SSPG) concentrations achieved during the last $60 \mathrm{~min}$ of a 180-min continuous infusion of somatostatin, insulin and glucose. Somatostatin, in this test, was used to suppress endogenous insulin production, and insulin and glucose were infused at a dose of $0.8 \mathrm{mU} \cdot \mathrm{kg}^{-1} \cdot \mathrm{min}^{-1}$ and $6 \mathrm{mg} \cdot \mathrm{kg}^{-1} \cdot \mathrm{min}^{-1}$, respectively. Normal subjects have SSPG below $6.6 \mathrm{mmol} \cdot \mathrm{l}^{-1}$ [11].

The kinetic study was carried out with patients in the fed state. Food intake, with a leucine poor diet $\left(1700 \mathrm{kcal} \cdot \mathrm{day}^{-1}\right.$, $55 \%$ carbohydrates, $39 \%$ fats and $7 \%$ proteins), was fractionated in small portions which were provided every $2 \mathrm{~h}$ starting $6 \mathrm{~h}$ prior to the tracer infusion up to the end of the study, to avoid important variations in apoB-100 hepatic secretion, as previously done by other groups $[10,12]$. The endogenous labelling of apoB was carried out by infusing $\mathrm{L}-\left[1-{ }^{13} \mathrm{C}\right]$ leucine (99 atom \%; Eurisotop, Saint Aubin, France), dissolved in $0.9 \% \mathrm{NaCl}$ solution. At 0800 hours each subject received a primed intravenous infusion of $0.7 \mathrm{mg} \cdot \mathrm{kg}^{-1}$ of tracer immediately followed by a $16 \mathrm{~h}$ constant infusion of $0.7 \mathrm{mg} \cdot \mathrm{kg}^{-1} \cdot \mathrm{h}^{-1}$. The day of the second kinetic experiment, intermediate acting human insulin was injected into Type II diabetic patients at 0800 and 2000 hours. Blood samples were drawn in tubes without anticoagulant but with a gel separator (Becton Dickinson, Meylan, France) at 0, 0.25, 0.75, 1, 1.5, 2, 3, 4, 6, 8, 10, 12, 14, 15 and $16 \mathrm{~h}$ after the primed infusion. Serum was separated by centrifugation for $10 \mathrm{~min}$ at $4{ }^{\circ} \mathrm{C}$ and $3000 \mathrm{~g}$. Sodium azide and aprotinin were added to the serum at a final concentration of $500 \mathrm{mg} \cdot \mathrm{l}^{-1}$ and $17 \mathrm{mg} \cdot \mathrm{l}^{-1}$, respectively.

Isolation of apo- $B$. Very low density lipoprotein [density (d) $<1.006 \mathrm{~g} / \mathrm{ml})$, IDL $(1.006<\mathrm{d}<1.019)$ and LDL $(1.019<\mathrm{d}<1.063)$ were isolated from plasma by sequential flotation ultracentrifugation, using a 50.4 rotor in a L7 apparatus (Beckman Instruments, Palo Alto, Calif., USA). Intermediate density lipoprotein and LDL fractions were then dialysed against a $10 \mathrm{mmol} \cdot \mathrm{l}^{-1}$ ammonium bicarbonate buffer pH 8.2 containing $0.01 \%$ EDTA and $0.013 \%$ sodium azide. Very low density lipoprotein fractions were delipidated $1 \mathrm{~h}$ at $-20^{\circ} \mathrm{C}$ using 10 volumes of diethylether-ethanol $3: 1$. ApoB100 was isolated by preparative SDS-PAGE: the delipidated apoB-100 containing material was solubilized in $0.05 \mathrm{~mol} / 1$ Tris buffer $\mathrm{pH} 8.6$, containing 3\% SDS, $3 \%$ mercaptoethanol and $10 \%$ glycerol and applied to a $3-\mathrm{mm}$ thick vertical slab gel ( $3 \%$ acrylamide). After staining with Coomassie blue R250 , apoB-100 was cut from the gel and hydrolysed in $\mathrm{HCl}$ $6 \mathrm{~mol} \cdot \mathrm{l}^{-1}$ for $16 \mathrm{~h}$ at $110^{\circ} \mathrm{C}$ under nitrogen vacuum. Samples were then centrifuged to remove polyacrylamide. Supernatants were lyophilized in a Speed Vac (Savant Instrument, Farmingdale, New York, USA). Lyophilized samples were dissolved in 50\% acetic acid, applied to an AG-50W-X8 200-400 
mesh cation exchange column (Bio-Rad, Richmond, Calif., USA), and amino acids were recovered by elution with $\mathrm{NH}_{4} \mathrm{OH} 4 \mathrm{~mol} \cdot \mathrm{1}^{-1}$ and lyophilized.

Determination of leucine enrichment by gas chromatography/ combustion/isotope ratio mass spectrometry (GC/C/IRMS). Amino acids were converted to N-acetyl O-propyl esters and were analysed on a Finnigan Mat Delta $\mathrm{C}$ isotope ratio mass spectrometer (Finnigan Mat, Bremen, Germany). The apparatus and the operating conditions have been previously described [13]. ${ }^{13} \mathrm{C}$ leucine enrichment was initially expressed in delta \%o and converted in tracer/tracee ratio prior to modelling [14-16].

Modelling. Data were analysed with the Simulation Analysis and Modelling (SAAM) II program (SAAM Institute, Inc., Seattle, Wash., USA) using the multicompartmental model shown in Figure 1. A forcing function, corresponding to the VLDL apoB-100 plateau enrichment, was used to drive the appearance of leucine tracer into the different lipoprotein fractions [17-18]. The delay compartment accounted for the time required for the synthesis and secretion of apoB-100 into the plasma. Compartments 1 and 2 represented plasma apoB VLDL, compartments 11 and 12 plasma apoB IDL. Compartments 2 and 12 turned over more slowly than compartments 1 and 11, respectively. Although the majority of IDL apoB was derived from VLDL, a direct IDL apoB input was sometimes required. A shunt from compartment 1 to 21 also improved the fit in some cases.

As the experiment was carried out in the steady state, fractional synthetic rate equalled fractional catabolic rate (FCR).

Direct FCR of VLDL apoB and FCR from VLDL to IDL or LDL were calculated as follows:

Direct FCR $\mathrm{VLDL}=\frac{M_{2} k(0,2)}{M_{1}+M_{2}}$

$\mathrm{FCR}_{\mathrm{VLDL} \text { to IDL or LDL }}=\frac{M_{1}(k(11,1)+k(21,1))}{M_{1}+M_{2}}$

where $\mathrm{k}(\mathrm{i}, \mathrm{j})$ is the fractional transfer coefficient from compartment $\mathrm{j}$ to $\mathrm{i}$. $\mathrm{M}_{\mathrm{j}}$ represents the mass (expressed as concentration per liter of plasma) of compartment $j$.

Total VLDL apoB FCR is the sum of direct $\mathrm{FCR}_{\mathrm{VLDL}}$ and $\mathrm{FCR}_{\mathrm{VLDL} \text { to IDL and LDL }}$.

Direct FCR of IDL apoB and FCR from IDL to LDL were calculated as follows:

Direct $\mathrm{FCR}_{\mathrm{IDL}}=\frac{M_{12} k(0,12)}{M_{11}+M_{12}}$

$\mathrm{FCR}_{\text {IDL to } \mathrm{LDL}}=\frac{M_{11} k(21,11)}{M_{11}+M_{12}}$

Total apoB IDL FCR is the sum of direct FCR IDL $_{\text {and }}$ $\mathrm{FCR}_{\mathrm{IDL} \text { to LDL}}$.

The FCR of LDL apoB was calculated as follows:

$\mathrm{FCR}_{\mathrm{LDL}}=k(0,21)$

For each lipoprotein fraction, residence time was calculated as the inverse of FCR.

Because Type II diabetic patients were obese, production rate in one lipoprotein fraction was the product of the total FCR and the apoB plasma concentration of that fraction. Thus, data were normalized to the plasma volume of each subject.

Analytical methods. Plasma glucose concentrations were measured by an enzymatic method (glucose oxidase) on a Vitros

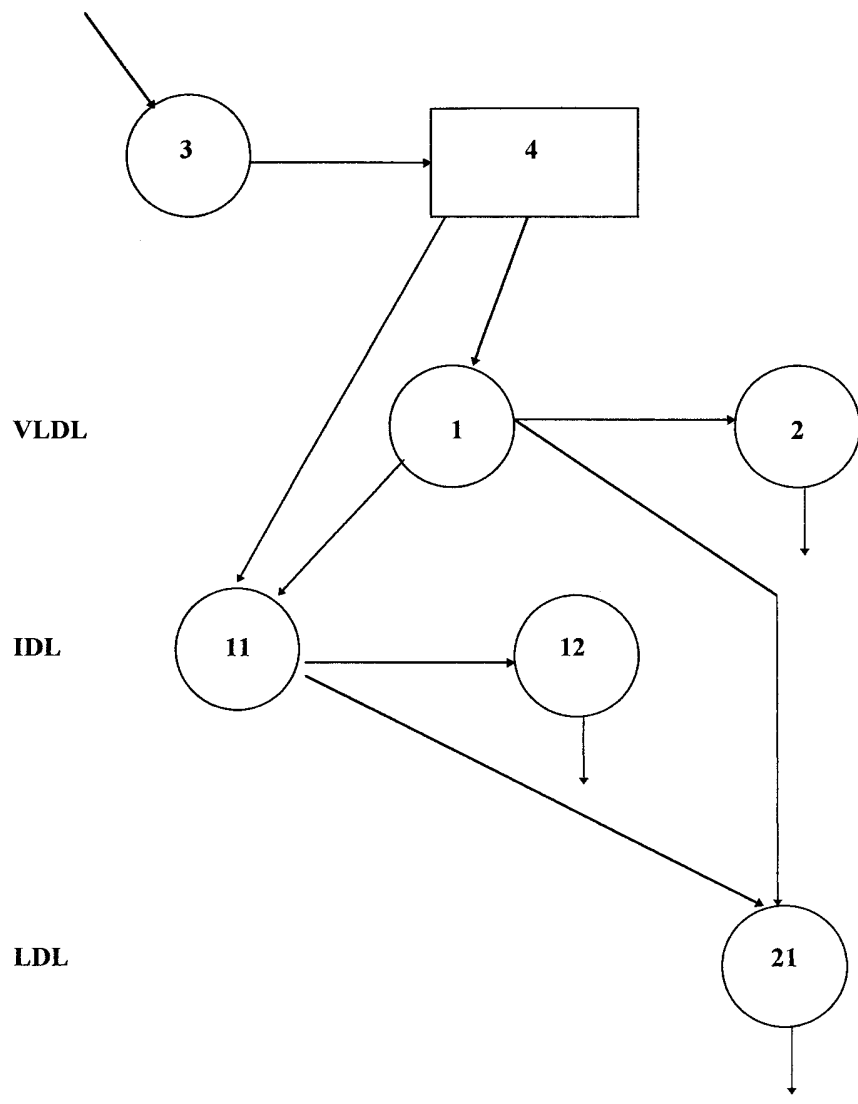

Fig. 1. Multicompartmental model for kinetic analysis of apoB metabolism. A forcing function corresponding to the VLDL apoB-100 plateau enrichment was used to drive the appearance of leucine tracer into the different lipoprotein fractions (compartment 3). Compartment 4 represents the delay. Compartments 1 and 2 represent plasma VLDL apoB, compartments 11 and 12 plasma IDL apoB, and compartment 21 plasma LDL apoB. Compartments 2 and 12 turn over more slowly than compartments 1 and 11, respectively. A direct IDL apoB input and a shunt from compartment 1 to 21 were required to improve the fit in some cases

750 analyser (Johnson \& Johnson Clinical Diagnostics, Rochester, N. Y., USA). $\mathrm{HbA}_{1 \mathrm{c}}$ was measured with ion exchange high performance liquid chromatography (Bio-Rad, Richmond, Calif., USA). Serum insulin concentrations were determined by radioimmunoassay (CIS Bio International, Gif sur Yvette, France). Total and HDL cholesterol, triglyceride and apoB concentrations were measured in a Cobas Fara analyser (Roche, Basel, Switzerland). Concentrations of total and HDL cholesterol were measured enzymatically (Boehringer Mannheim, Mannheim, Germany), after a magnesium phosphotungstate precipitation for HDL cholesterol. Triglycerides were quantified with an enzymatic method (Roche, Basel, Switzerland). apoB concentrations were measured by immunoturbidimetry (Boehringer Mannheim).

The mean apparent diameter of plasma LDL was determined by native polyacrylamide gel electrophoresis in 40-300 g/l gradient gels according to the procedure described previously $[19,20]$.

Statistical analysis. Results are expressed as means \pm SD. Statistical calculations were done using the SPSS software package. Control and diabetic groups were compared using the 
Table 1. Clinical and biological characteristics of study subjects

\begin{tabular}{|c|c|c|c|}
\hline & $\begin{array}{l}\text { Type II diabetics } \\
\text { before insulin therapy } \\
(n=6)\end{array}$ & $\begin{array}{l}\text { Type II diabetics } \\
\text { after insulin therapy } \\
(n=6)\end{array}$ & $\begin{array}{l}\text { Control subjects } \\
(n=5)\end{array}$ \\
\hline Age (years) & $52.8 \pm 9.7$ & & $22.4 \pm 1.1$ \\
\hline Weight $(\mathrm{kg})$ & $87.7 \pm 11.6^{\mathrm{a}}$ & $87.8 \pm 10.0^{\mathrm{d}}$ & $65 \pm 9$ \\
\hline $\mathrm{BMI}\left(\mathrm{kg} \cdot \mathrm{m}^{-2}\right)$ & $30.5 \pm 3.2^{\mathrm{b}}$ & $30.6 \pm 3.5^{\mathrm{e}}$ & $21.8 \pm 0.9$ \\
\hline Fasting triglycerides $\left(\mathrm{mmol} \cdot \mathrm{l}^{-1}\right)$ & $3.18 \pm 2.35^{\mathrm{b}}$ & $2.08 \pm 0.65^{\mathrm{c}, \mathrm{e}}$ & $0.60 \pm 0.18$ \\
\hline HDL cholesterol $\left(\mathrm{mmol} \cdot \mathrm{l}^{-1}\right)$ & $0.97 \pm 0.20^{\mathrm{b}}$ & $0.97 \pm 0.26^{\mathrm{e}}$ & $1.64 \pm 0.31$ \\
\hline Apo B $\left(g \cdot 1^{-1}\right)$ & $1.22 \pm 0.62^{\mathrm{a}}$ & $1.15 \pm 0.50^{\mathrm{c}, \mathrm{d}}$ & $0.76 \pm 0.11$ \\
\hline Fasting blood glucose $\left(\mathrm{mmol} \cdot \mathrm{l}^{-1}\right)$ & $11.93 \pm 1.89^{\mathrm{b}}$ & $8.16 \pm 1.11^{\mathrm{c}, \mathrm{e}}$ & $4.38 \pm 0.28$ \\
\hline $\mathrm{HbA}_{1 \mathrm{c}}(\%)$ & $9.3 \pm 1.5$ & $7.8 \pm 1.4^{\mathrm{c}}$ & \\
\hline Fasting insulin $\left(\mathrm{pmol} \cdot \mathrm{1}^{-1}\right)$ & $75.2 \pm 53.0$ & & \\
\hline $\mathrm{SSPG}\left(\mathrm{mmol} \cdot \mathrm{l}^{-1}\right)$ & $13.21 \pm 2.33$ & $10.82 \pm 5.83$ & \\
\hline
\end{tabular}

Table 2. Characteristics of the different apoB-containing lipoproteins from Type II diabetic and control subjects

\begin{tabular}{lccc}
\hline & $\begin{array}{l}\text { Type II diabetic } \\
\text { before insulin therapy } \\
(n=6)\end{array}$ & $\begin{array}{l}\text { Type II diabetic } \\
\text { after insulin therapy } \\
(n=6)\end{array}$ & $\begin{array}{l}\text { Control subjects } \\
(n=5)\end{array}$ \\
\hline VLDL TG/apoB & $26.51 \pm 4.79$ & $21.68 \pm 6.95^{\mathrm{b}}$ & $18.55 \pm 8.40$ \\
IDL TG/apoB & $3.56 \pm 0.41^{\mathrm{a}}$ & $3.19 \pm 0.24^{\mathrm{c}}$ & $2.83 \pm 0.58$ \\
LDL TG/apoB & $0.54 \pm 0.21^{\mathrm{a}}$ & $0.44 \pm 0.04^{\mathrm{c}}$ & $0.32 \pm 0.08$ \\
LDL mean diameter $(\mathrm{nm})$ & $25.6 \pm 0.2^{\mathrm{a}}$ & $25.9 \pm 0.8^{\mathrm{d}}$ & $27.5 \pm 0.7$ \\
\hline
\end{tabular}

The TG/apoB ratios were calculated from data expressed as $\mathrm{mmol} \cdot \mathrm{l}^{-1}$ for TG and $\mathrm{g} \cdot \mathrm{l}^{-1}$ for apoB

Values are mean \pm SD

${ }^{a} p<0.05$ Type II diabetic before insulin therapy vs control subjects

non-parametric Mann-Whitney U-test. Before and after insulin therapy diabetic subjects were compared using the nonparametric Wilcoxon matched-pair test. Correlation coefficients were calculated by the Spearman test. $P$-values less than 0.05 were considered to be statistically significant.

\section{Results}

Metabolic parameters. Insulin therapy improved significantly glycaemic control in Type II diabetic patients as assessed by fasting blood glucose concentration $\left(8.16 \pm 1.11\right.$ vs $\left.11.93 \pm 1.89 \mathrm{mmol} \cdot 1^{-1} ; p<0.05\right)$ and $\mathrm{HbA}_{1 \mathrm{c}}(7.8 \pm 1.4$ vs $9.3 \pm 1.5 \% ; p<0.05)$ (Table 1). Insulin sensitivity was evaluated in Type II diabetic patients by calculating the SSPG value during the insulin suppressive test. Insulin treatment of 2 months did not significantly improve insulin sensitivity in our patients (Table 1).

Plasma lipids. Before the introduction of insulin therapy Type II diabetic patients had high plasma triglyceride concentrations both in the fasting and in
${ }^{\mathrm{b}} p<0.05$ Type II diabetic subjects after vs before insulin therapy

${ }^{\mathrm{c}} p<0.05 ;{ }^{\mathrm{d}} p<0.01$ Type II diabetic after insulin therapy vs control subjects

the fed state, compared with control subjects $(3.18 \pm 2.35$ vs $0.60 \pm 0.18$ and $3.87 \pm 2.10$ vs $0.90 \pm$ $0.23 \mathrm{mmol} \cdot 1^{-1}$, respectively; $p<0.01$ ) (Table 1 ). On insulin therapy, plasma triglycerides fell by $35 \%$ in the fasting state $(p<0.05)$ and by $24 \%$ in the fed state (not significant). Nevertheless, plasma triglycerides remained higher in Type II diabetic than in healthy subjects, both in the fasting and in the fed state $(p<0.01)$. Total plasma cholesterol concentration was initially comparable between patients and control subjects and was not modified by insulin treatment in Type II diabetic patients. High density lipoprotein (HDL) cholesterol concentration was reduced in Type II diabetic patients before insulin therapy $\left(0.97 \pm 0.20\right.$ vs $\left.1.64 \pm 0.31 \mathrm{mmol} \cdot \mathrm{l}^{-1}\right)$ and remained unchanged with insulin treatment. Very low density lipoprotein, IDL, and LDL were triglyceride-enriched in Type II diabetic patients as assessed by the triglyceride/apoB ratio in each lipoprotein fraction (Table 2). On insulin therapy we observed a significant fall of the triglyceride/apoB ratio only in the VLDL particles $(21.68 \pm 6.95$ vs $26.51 \pm 4.79$; $p<0.05)$. The mean LDL particle size was signifi- 

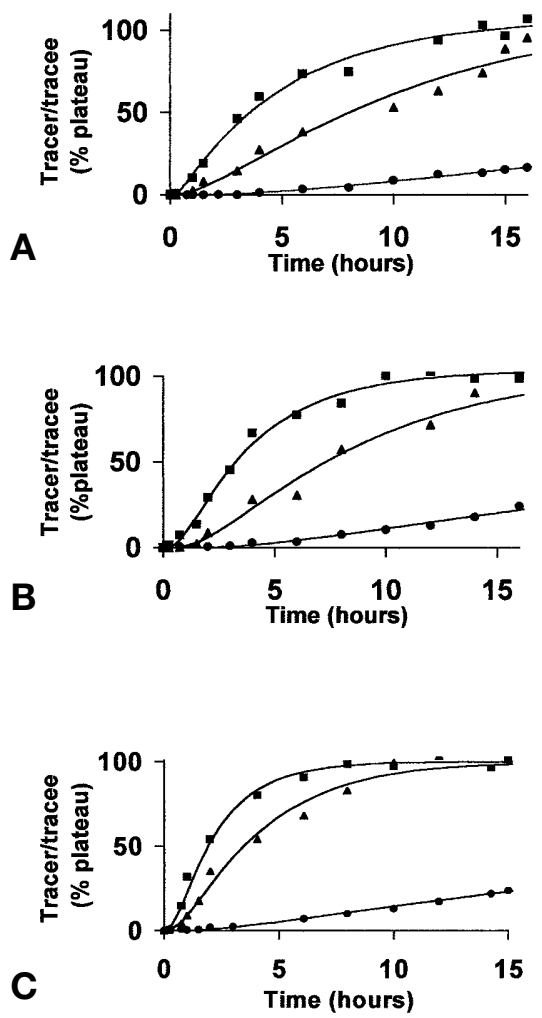

Fig. 2 A-C. $\left[{ }^{13} \mathrm{C}\right]$ Leucine enrichment curves of human apoB100 in one Type II diabetic patient before (A) and 2 months after the introduction of insulin therapy (B) and one control subject $(\mathbf{C})$. Tracer/tracee values (mean of triplicates) from VLDL (squares), IDL (triangles) and LDL (circles) were measured by GC/C/IRMS. The curves were obtained by compartmental modelling

cantly smaller in Type II diabetes $(25.6 \pm 0.2$ vs $27.5 \pm 0.7 \mathrm{~nm} ; p<0.05)$ and was unchanged on insulin therapy.

Apo B kinetic. Kinetic curves are shown in Figure 2, for one control subject and one Type II diabetic patient before and after the start of insulin therapy.

Figure 3 represents apoB plasma concentration in VLDL, IDL and LDL fractions in function of time during the kinetic experiment for one representative studied subject. The coefficient of variation throughout the study was respectively $4.8,9.2$ and $5.1 \%$ for plasma VLDL, IDL and LDL apoB. The coefficient of variation for VLDL TG/apoB ratio was $11.3 \%$.

ApoB pool size, production rate and fractional catabolic rate are shown in Table 3 for VLDL, IDL and LDL particles and for each Type II diabetic patient. Before insulin therapy VLDL apoB plasma concentration was 3.49-fold increased in Type II diabetic patients compared with control subjects $(p<0.01)$, related both to a $41 \%$ increase of VLDL apoB production rate $(p<0.05)$ and to a $61 \%$ decrease of the transformation rate of VLDL into IDL and LDL $(p<0.05)$. VLDL apoB production rate re-
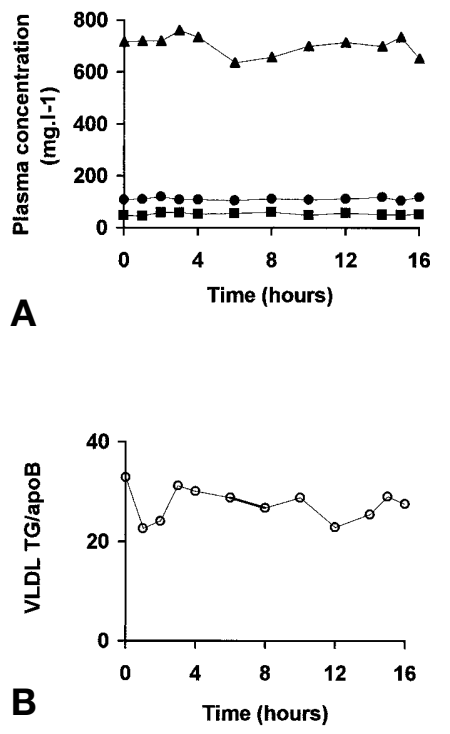

Fig.3A,B. Evolution of VLDL (circles), IDL (squares) and LDL (triangles) apoB concentration (A), and of VLDL TG/ apoB (B) in one insulin-treated Type II diabetic subject during the kinetic experiment. In this patient, the coefficient of variation for these parameters throughout the study was respectively $4.8,9.2,5.1$ and $11.3 \%$. The values were similar in all studied subjects

mained significantly higher in Type II diabetic patients than in control subjects after adjustment for age. On insulin therapy we observed a $23 \%$ decrease of VLDL apoB plasma concentration $(p<0.05)$, related to a significant increase of VLDL apoB fractional catabolic rate towards IDL and LDL $\left(0.20 \pm 0.08\right.$ vs $0.14 \pm 0.07$ pool $\left.\cdot \mathrm{h}^{-1} ; p<0.05\right)$. Insulin did not reduce VLDL apoB overproduction. Despite the beneficial effect of insulin therapy on VLDL apoB metabolism, VLDL apoB plasma concentration remained higher in Type II diabetic patients than in control subjects $(p<0.01)$ and VLDL apoB fractional catabolic rate towards IDL or LDL was not normalized $(p<0.05)$.

IDL apoB plasma concentration was initially $4.52-$ fold increased in Type II diabetic patients $(p<0.01)$, related to a $78 \%$ decrease of IDL transformation into LDL $(p<0.01)$ and was not significantly modified by insulin therapy. Nevertheless, apoB IDL turn-over was accelerated with insulin treatment. Indeed, we observed both an increase of IDL apoB production rate $\left(22.6 \pm 9.2\right.$ vs $18.2 \pm 9.6 \mathrm{mg} \cdot \mathrm{l}^{-1} \cdot \mathrm{h}^{-1}$, $p<0.05)$ and of IDL apoB catabolic rate towards LDL $\left(0.34 \pm 0.22\right.$ vs $0.22 \pm 0.16$ pool $\left.\cdot \mathrm{h}^{-1} ; p<0.05\right)$. Intermediate density lipoprotein apoB catabolic rate towards LDL remained, however, diminished in Type II diabetic patients compared with control subjects $(p<0.01)$.

Before insulin treatment LDL apoB FCR was significantly decreased in Type II diabetic patients compared with control subjects $(0.018 \pm 0.004$ vs 
Table 3. ApoB kinetic parameters in 6 Type II diabetic patients before and during insulin therapy and in 5 control subjects

\begin{tabular}{|c|c|c|c|c|c|c|c|c|c|c|}
\hline \multicolumn{4}{|c|}{ VLDL apoB } & \multicolumn{4}{|c|}{ IDL apoB } & \multicolumn{3}{|c|}{ LDL apoB } \\
\hline \multirow{2}{*}{$\begin{array}{l}\text { Plasma } \\
\text { pool } \\
\left(\mathrm{mg} \cdot \mathrm{l}^{-1}\right)\end{array}$} & \multirow[t]{2}{*}{$\begin{array}{l}\text { Production } \\
\left(\mathrm{mg} \cdot \mathrm{l}^{-1} \cdot \mathrm{h}^{-1}\right)\end{array}$} & \multicolumn{2}{|c|}{$\begin{array}{l}\text { Fractional rate } \\
\left(\mathrm{pool} \cdot \mathrm{h}^{-1}\right)\end{array}$} & \multirow{2}{*}{$\begin{array}{l}\text { Plasma } \\
\text { pool } \\
\left(\mathrm{mg} \cdot \mathrm{l}^{-1}\right)\end{array}$} & \multirow[t]{2}{*}{$\begin{array}{l}\text { Production } \\
\left(\mathrm{mg} \cdot \mathrm{l}^{-1} \cdot \mathrm{h}^{-1}\right)\end{array}$} & \multicolumn{2}{|c|}{$\begin{array}{l}\text { Fractional rate } \\
\left(\text { pool } \cdot \mathrm{h}^{-1}\right)\end{array}$} & \multirow{2}{*}{$\begin{array}{l}\text { Plasma } \\
\text { pool } \\
\left(\mathrm{mg} \cdot \mathrm{l}^{-1}\right)\end{array}$} & \multirow[t]{2}{*}{$\begin{array}{l}\text { Production } \\
\left(\mathrm{mg} \cdot \mathrm{l}^{-1} \cdot \mathrm{h}^{-1}\right)\end{array}$} & \multirow{2}{*}{$\begin{array}{l}\text { Fractional } \\
\text { catabolic rate } \\
\left(\text { pool } \cdot \mathrm{h}^{-1}\right)\end{array}$} \\
\hline & & $\begin{array}{l}\text { Direct } \\
\text { catabolism }\end{array}$ & $\begin{array}{l}\text { Transfer } \\
\text { to IDL } \\
\text { or LDL }\end{array}$ & & & $\begin{array}{l}\text { Direct } \\
\text { catabolism }\end{array}$ & $\begin{array}{l}\text { Transfer } \\
\text { to LDL }\end{array}$ & & & \\
\hline
\end{tabular}

\begin{tabular}{|c|c|c|c|c|c|c|c|c|c|c|c|}
\hline \multicolumn{12}{|c|}{$\begin{array}{l}\text { Type II diabetic subjects } \\
\text { before insulin }\end{array}$} \\
\hline 1 & 95 & 33.4 & 0.08 & 0.27 & 42 & 25.5 & 0.08 & 0.53 & 903 & 22.3 & 0.025 \\
\hline 2 & 110 & 23.7 & 0.05 & 0.17 & 51 & 19.1 & 0.15 & 0.23 & 709 & 11.6 & 0.016 \\
\hline 3 & 159 & 31.7 & 0.07 & 0.13 & 70 & 20.5 & 0.13 & 0.16 & 731 & 11.3 & 0.015 \\
\hline 4 & 336 & 26.9 & 0 & 0.08 & 152 & 30.3 & 0.00 & 0.20 & 2111 & 30.2 & 0.014 \\
\hline 5 & 150 & 32.2 & 0.13 & 0.09 & 69 & 8.0 & 0.00 & 0.12 & 692 & 12.9 & 0.019 \\
\hline 6 & 97 & 18.1 & 0.05 & 0.14 & 76 & 6.0 & 0.00 & 0.08 & 757 & 13.2 & 0.018 \\
\hline Mean \pm SD & $158 \pm 91^{\mathrm{b}}$ & $27.7 \pm 6.0^{\mathrm{a}}$ & $0.06 \pm 0.04$ & $0.14 \pm 0.07^{\mathrm{a}}$ & $77 \pm 39^{b}$ & $18.2 \pm 9.6$ & $0.06 \pm 0.07$ & $0.22 \pm 0.16^{\mathrm{b}}$ & $984 \pm$ & $55816.9 \pm 7.7$ & $0.018 \pm 0.004^{\mathrm{a}}$ \\
\hline \multicolumn{12}{|c|}{$\begin{array}{l}\text { Type II diabetic subjects } \\
\text { after insulin }\end{array}$} \\
\hline 1 & 85 & 30.5 & 0.01 & 0.35 & 37 & 29.7 & 0.04 & 0.76 & 1008 & 28.2 & 0.028 \\
\hline 2 & 99 & 27.9 & 0.07 & 0.21 & 47 & 20.7 & 0.06 & 0.38 & 754 & 18.1 & 0.024 \\
\hline 3 & 152 & 34.2 & 0.09 & 0.13 & 75 & 23.0 & 0.11 & 0.20 & 713 & 15.0 & 0.021 \\
\hline 4 & 182 & 36.4 & 0 & 0.20 & 87 & 36.3 & 0.07 & 0.34 & 1923 & 30.8 & 0.016 \\
\hline 5 & 135 & 16.8 & 0 & 0.12 & 58 & 12.2 & 0.05 & 0.16 & 730 & 15.3 & 0.021 \\
\hline 6 & 75 & 14.5 & 0.01 & 0.18 & 61 & 13.8 & 0.00 & 0.23 & 661 & 13.9 & 0.021 \\
\hline Mean \pm SD & $121 \pm 42^{\mathrm{c}, \mathrm{e}}$ & $26.7 \pm 9.1$ & $0.03 \pm 0.04$ & $0.20 \pm 0.08^{\mathrm{c}, \mathrm{d}}$ & $61 \pm 18^{\mathrm{e}}$ & $22.6 \pm 9.2^{c}$ & $0.06 \pm 0.04$ & $0.34 \pm 0.22^{\mathrm{c}, \mathrm{e}}$ & $965 \pm$ & $48520.2 \pm 7.4^{c}$ & $0.022 \pm 0.004^{\mathrm{c}}$ \\
\hline \multicolumn{12}{|c|}{ Control subjects } \\
\hline Mean $\pm S D$ & $48 \pm 20$ & $19.6 \pm 2.4$ & $0.08 \pm 0.08$ & $0.36 \pm 0.10$ & $17 \pm 3$ & $18.4 \pm 3.2$ & $0.09 \pm 0.07$ & $1.02 \pm 0.13$ & $699 \pm$ & $10616.9 \pm 2.3$ & $0.025 \pm 0.004$ \\
\hline
\end{tabular}

${ }^{\mathrm{a}} p<0.05 ;{ }^{\mathrm{b}} p<0.01$ Type II diabetic before insulin therapy vs control subjects

${ }^{c} p<0.05$ Type II diabetic subjects after vs before insulin therapy

${ }^{\mathrm{d}} p<0.05 ;{ }^{\mathrm{e}} p<0.01$ Type II diabetic after insulin therapy vs control subjects

$0.025 \pm 0.004$ pool $\left.\cdot \mathrm{h}^{-1} ; p<0.05\right)$, even after adjustment for age. The most spectacular effect induced by insulin therapy in these patients was the almost normalization of LDL apoB FCR (0.022 \pm 0.004 pool $\left.\cdot \mathrm{h}^{-1} ; p<0.05\right)$. Low density lipoprotein apoB production rate has also been significantly increased by insulin treatment $(20.2 \pm 7.4$ vs $16.9 \pm$ $\left.7.7 \mathrm{mg} \cdot \mathrm{l}^{-1} \cdot \mathrm{h}^{-1} ; p<0.05\right)$. Due to the opposite effect of production and catabolism increases, LDL apoB plasma concentration was unchanged by insulin treatment.

The mean residence time of VLDL, IDL and LDL particles, initially prolonged in Type II diabetic patients compared with control subjects $[5.84 \pm 3.38$ vs $2.41 \pm 0.72 \mathrm{~h} \quad(p<0.05) ; \quad 5.67 \pm 4.2 \quad$ vs $\quad 0.9 \pm 0.1 \mathrm{~h}$ $(p<0.01) ; 57.8 \pm 10.3$ vs $41.6 \pm 6.5 \mathrm{~h}(p<0.05)$, respectively], was significantly decreased by insulin therapy $[4.83 \pm 1.83$ vs $5.84 \pm 3.38 \mathrm{~h} \quad(p<0.05)$; $3.06 \pm 1.36$ vs $5.67 \pm 4.2 \mathrm{~h} \quad(p<0.05) ; 47.1 \pm 8.9$ vs $57.8 \pm 10.3 \mathrm{~h}(p<0.05)$, respectively].

\section{Discussion}

It is now well established that Type II diabetes is associated with multiple potentially atherogenic abnormalities of lipoprotein metabolism. This stable isotope kinetic study was designed to explore the effect of insulin treatment on apoB-containing lipoprotein metabolism in Type II diabetic patients with poor glycaemic control. We chose to study the meta- bolism of apoB in the postprandial state, since this state is the most frequent for humans during a $24 \mathrm{~h}$ period. Moreover, many data suggest that atherosclerosis could be partially a postprandial phenomenon [21]. The daily food intake was divided into small portions taken by the subjects every $2 \mathrm{~h}$, as done previously by several groups $[10,12]$. With this protocol the VLDL TG/apoB ratio and the apoB concentration in the different lipoprotein fractions remained constant throughout the kinetic study, indicating that the subjects were in steady state.

Before the introduction of insulin therapy, the apoB-containing lipoprotein metabolism was greatly impaired in the Type II diabetic patients who participated in our study, in agreement with previous works [2-6]. These patients had an increased plasma concentration of triglyceride-enriched VLDL particles, related both to an increased hepatic secretion rate and a strongly decreased catabolism towards IDL or LDL. Intermediate density lipoprotein apoB catabolism was also decreased, resulting in an increased number of circulating IDL particles. Finally, LDL apoB concentration was not significantly different in Type II diabetic patients and control subjects but LDL apoB catabolic rate was significantly decreased in these patients, resulting in a prolonged intravascular residence time, which is likely to be harmful.

Insulin therapy partially corrected the defects observed on the catabolic rate of apoB-containing lipoproteins in Type II diabetes. The $23 \%$ decrease of VLDL apoB plasma concentration induced by insulin 
therapy was entirely due to the improvement of their catabolic rate. Indeed, insulin treatment had no effect on the VLDL apoB overproduction shown by our Type II diabetic patients. Synthesis of IDL apoB from VLDL was increased on insulin treatment, but its transformation into LDL apoB was also accelerated. Thus, plasma IDL apoB concentration was not notably changed. Finally, the increased synthetic rate of LDL apoB from IDL was counterbalanced by the normalization of LDL apoB catabolism, resulting in a constant plasma concentration.

A decrease of hepatic VLDL apoB production could not be achieved in Type II diabetic patients by a 2-month insulin treatment. Insulin interacts with hepatic apoB secretion by at least two mechanisms. In healthy subjects, euglycaemic hyperinsulinaemic clamp studies have shown that insulin suppresses the production of VLDL1 particles by decreasing the availability of free fatty acids to the liver and by exerting a direct suppressive effect on apoB production [22]. In Type II diabetic subjects, euglycaemic hyperinsulinaemic clamp studies yielded contradictory results, reporting either a twofold decrease of VLDL apoB production [23], or the inability of insulin to suppress VLDL1 production despite efficient suppression of serum non-esterified fatty acids and euglycaemic conditions [24]. Contrary to hyperinsulinaemic clamp tests, our study gave us the opportunity to examine the effect on apoB metabolism of longterm insulin administration at more physiologic doses. We failed to show any inhibitory effect of insulin therapy on hepatic apoB secretion. The resistance to the suppressive effect of insulin on hepatic apoB production has also been found in obese non-diabetic subjects [25], indicating that the presence of this abnormality in Type II diabetic patients is probably a characteristic feature of the insulin resistance state and that it could appear at a very early stage in these patients. Insulin sensitivity as assessed by the SSPG value during insulin treatment was not much improved. Consequently, the persistence of apoB VLDL overproduction in insulin-treated Type II diabetic patients is not surprising.

The number of secreted VLDL particles was not modified with insulin therapy in our Type II diabetic patients, but the VLDL TG/apoB ratio significantly decreased. It has been reported previously that neither sulphonylurea nor insulin therapy diminished apoB secretion rate in Type II diabetic patients, whereas glycaemia, plasma non-esterified fatty acid concentration and hepatic triglyceride production were all reduced $[10,26]$. We did not measure the triglyceride secretion rate in our study. Nevertheless, the decreased TG/apoB ratio after the introduction of insulin therapy is consistent with the production of denser and less TG-enriched VLDL. In that case, the acceleration of VLDL, IDL and LDL apoB catabolism could be explained by the incorporation of
apoB in VLDL particles being more quickly catabolized throughout the VLDL $\rightarrow$ IDL $\rightarrow$ LDL cascade, as shown by selective radioactive labelling of VLDL1 and VLDL2 [27, 28].

Alternatively, the decrease of the VLDL TG/apoB ratio and the acceleration of the transformation of VLDL and IDL respectively into IDL and LDL in insulin-treated Type II diabetic patients possibly indicates that the delipidation process in the VLDL $\rightarrow$ IDL $\rightarrow$ LDL cascade has been improved. Indeed, insulin therapy has been shown to partially restore the adipose tissue lipoprotein lipase activity, which is likely to contribute to the better VLDL lipolysis observed in insulin-treated Type II diabetic patients $[8,10]$.

This study shows for the first time that in Type II diabetic patients who have a decreased LDL catabolic rate insulin therapy could restore this catabolism to a normal level, leading to a normal LDL particle residence time. In moderately severe Type II diabetes, the decrease of LDL catabolism is multifactorial. The glycation of apoB [29, 30], as well as the small size and the triglyceride enrichment of LDL in Type II diabetic subjects [30-33] have been shown to diminish the affinity of these particles to their receptor. The improvement of glycaemic control as assessed by the decrease of both $\mathrm{HbA}_{1 \mathrm{c}}$ and fasting glycaemia in our patients is consistent with a lesser apoB glycation and subsequently a greater affinity of LDL to their receptor. On the contrary, insulin therapy had only little effect on the high triglyceride content and the small size of LDL, suggesting that modifications of size and triglyceride content of LDL are not likely to be involved in the improvement of LDL catabolism. On the other hand, the increased expression of LDL receptors by insulin therapy could probably contribute to the increase of LDL catabolism that we observed [34].

The prolonged LDL residence time observed in Type II diabetic patients before the introduction of insulin therapy is likely to be harmful because it increases the chances of glycation and oxidation of LDL particles, as already suggested [35, 36]. Oxidative processes are involved in atherogenesis. Indeed, the uptake of oxidative LDL by macrophages in the vessel wall induces the formation of foam cells, one of the first steps in the development of atherosclerotic lesions [37]. Low density lipoprotein glycation is likely to be harmful by promoting LDL oxidation and because glycated LDL is more easily taken up by macrophages than normal LDL [38-40]. Situations in which LDL plasma residence time is shortened, such as statin treatment, is accompanied by a reduction of LDL oxidizability [41]. Moreover, it has been shown that an $18 \%$ reduction of LDL residence time under simvastatin treatment induced a $59 \%$ decrease of LDL glycation in Type II diabetic patients [42]. The normalization of LDL residence time in- 
duced by insulin therapy in our patients is to our mind of major importance, as LDL is exposed to glycative and oxidative modifications for a shorter time. Thus, even if insulin therapy does not modify LDL apoB concentration in Type II diabetic patients, it is likely to make LDL particles less atherogenic by decreasing their intravascular residence time and thus by decreasing their susceptibility to glycation and oxidation.

In conclusion, our stable isotope kinetic study has shown that a 2-month insulin treatment significantly improves the apoB-containing lipoprotein metabolism in Type II diabetic patients. Indeed, in insulintreated Type II diabetic patients the delipidation process through the VLDL $\rightarrow$ IDL $\rightarrow$ LDL cascade is faster, and we observed a normalization of the LDL apoB catabolic rate in patients for whom it was initially decreased. The acceleration of all apoB-containing lipoprotein catabolism indicates that the residence time of these particles is shorter which is likely to make them less harmful by decreasing their susceptibility to glycation and oxidation.

Acknowledgements. We are indebted to V. Jost of the pharmaceutical department for preparation of ${ }^{13} \mathrm{C}$-leucine, C. Gibassier for invaluable dietary assistance and the study subjects for participating.

This investigation was supported by the University of Burgundy, the Regional Council of Burgundy, and the National Institute of Health and Medical Research (INSERM).

\section{References}

1. Pyörälä K, Laakso M, Uusitupa M (1987) Diabetes and atherosclerosis: an epidemiologic view. Diabetes Metab Rev 2: 464-524

2. Kissebah AH, Alfarsi S, Evans DJ, Adams PW (1982) Integrated regulation of very low density lipoprotein triglycerides and apolipoprotein-B kinetics in non-insulin-dependent diabetes mellitus. Diabetes 31: 217-225

3. Taskinen MR, Beltz WF, Harper I et al. (1986) Effects of NIDDM on very-low-density lipoprotein triglyceride and apolipoprotein B metabolism. Study before and after sulfonylurea therapy. Diabetes 35: 1268-1277

4. Howard BV, Abbott WGH, Egusa G, Taskinen MR (1987) Coordination of very-low-density lipoprotein triglyceride and apolipoprotein B metabolism in humans: effects of obesity and non-insulin-dependent diabetes mellitus. Am Heart J 113: 522-526

5. Howard BV, Abbott WGH, Beltz WF et al. (1987) Integrated study of low density lipoprotein metabolism and very low density lipoprotein metabolism in non-insulin-dependent diabetes. Metabolism 36: 870-877

6. Cummings MH, Watts GF, Umpleby AM et al. (1995) Increased hepatic secretion of very-low-density lipoprotein apolipoprotein B-100 in NIDDM. Diabetologia 38: 959-967

7. Kissebah AH, Alfarsi S, Evans DJ, Adams PW (1983) Plasma low density lipoprotein transport kinetics in noninsulindependent diabetes mellitus. J Clin Invest 71: 655-667

8. Taskinen MR, Kuusi T, Helve E, Nikkilä EA, Yki-Järvinen H (1988) Insulin therapy induces antiatherogenic changes of serum lipoproteins in noninsulin-dependent diabetes. Arteriosclerosis 8: 168-177

9. Bagdade JD, Buchanan WE, Kuusi T, Taskinen MR (1990) Persistent abnormalities in lipoprotein composition in noninsulin-dependent diabetes after intensive insulin therapy. Arterioscl 10: 232-239

10. Taskinen MR, Packard CJ, Sheperd J (1990) Effect of insulin therapy on metabolic fate of apolipoprotein B-containing lipoproteins in NIDDM. Diabetes 39: 1017-1027

11. Shen DC, Shien SM, Fuh MMT, Wu DA, Chen YDI, Reaven GM (1988) Resistance to insulin-stimulated-glucose uptake in patients with hypertension. J Clin Endocrinol Metab 66: 580-583

12. Vergès B, Rader D, Schaefer J et al. (1994) In vivo metabolism of apolipoprotein A-IV in severe hypertriglyceridemia: a combined radiotracer and stable isotope kinetic study. J Lipid Res 35: 2280-2291

13. Pont F, Duvillard L, Maugeais C et al. (1997) Isotope Ratio Mass Spectrometry, compared with conventional mass spectrometry in kinetic studies at low and high enrichment levels: application to lipoprotein kinetics. Anal Biochem 248: 277-287

14. Pont F, Duvillard L, Vergès B, Gambert P (1998) Development of compartmental models in stable isotope experiments: application to lipoprotein metabolism. Arterioscler Thromb Vasc Biol 18: 853-860

15. Cobelli C, Toffolo G, Foster DM (1992) Tracer-to-tracee ratio for analysis of stable isotope tracer data: link with radioactive kinetic formalism. Am J Physiol 262: E968-E975

16. Cobelli C, Toffolo G, Bier DM, Nosadini R (1987) Models to interpret kinetic data in stable isotope tracer studies. Am J Physiol 253: E551-E564

17. Millar JS, Lichtenstein AH, Cuchel M et al. (1995) Impact of age on the metabolism of VLDL, IDL, and LDL apolipoprotein B-100 in men. J Lipid Res 36: 1155-1167

18. Maugeais C, Ouguerram K, Krempf M et al. (1996) A minimal model using stable isotopes to study the metabolism of apolipoprotein B-containing lipoproteins in humans. Diabetes Metab 22: 57-63

19. Lagrost L, Athias A, Herbeth B et al. (1996) Opposite effects of cholesteryl transfer protein and phospholipid transfer protein on the size distribution of plasma high density lipoproteins. J Biol Chem 271: 19058-19065

20. Viens L, Athias A, Lizard G et al. (1996) Effect of lipid transfer activity and lipolysis on low density lipoprotein (LDL) oxidizability: evidence for lipolysis-generated nonesterified fatty acids as inhibitors of LDL oxidation. J Lipid Res 37: 2179-2192

21. Zilversmit DB (1979) Atherogenesis: a postprandial phenomenon. Circulation 60: 473-485

22. Malmström R, Packard CJ, Caslake M et al. (1998) Effects of insulin and acipimox on VLDL1 and VLDL2 apolipoprotein B production in normal subjects. Diabetes 47: 779-787

23. Cummings MH, Watts GF, Umpleby AM et al. (1995) Acute hyperinsulinemia decreases the hepatic secretion of very-low-density lipoprotein apolipoprotein B-100 in NIDDM. Diabetes 44: 1059-1065

24. Malmström R, Packard CJ, Caslake M et al. (1997) Defective regulation of triglyceride metabolism by insulin in the liver in NIDDM. Diabetologia 40: 454-462

25. Lewis GF, Uffelman KD, Szeto LW, Steiner G (1993) Effects of acute hyperinsulinemia on VLDL triglyceride and VLDL apo $B$ production in normal weight and obese individuals. Diabetes 42: 833-842

26. Taskinen MR, Beltz WF, Harper I et al. (1986) Effects of NIDDM on very-low-density lipoprotein triglyceride and 
apolipoprotein B metabolism: studies before and after sulfonylurea therapy. Diabetes 35: 1268-1277

27. Packard CJ, Munro A, Lorimer AR, Gotto AM, Shepherd J (1984) Metabolism of apolipoprotein B in large triglyceride-rich very low density lipoproteins of normal and hypertriglyceridemic subjects. J Clin Invest 74: 2178-2192

28. Packard CJ, Gaw A, Demant T, Shepherd J (1995) Development and application of a multicompartmental model to study very low density lipoprotein subfraction metabolism. J Lipid Res 36: 172-187

29. Steinbrecher UP, Witztum JL (1984) Glucosylation of lowdensity lipoproteins to an extent comparable to that seen in diabetes slows their catabolism. Diabetes 33: 130-134

30. Krämer-Guth A, Quaschning T, Galle J et al. (1997) Structural and compositional modifications of diabetic low-density lipoproteins influence their mediator-mediated uptake by hepatocytes. Eur J Clin Invest 27: 460-468

31. Nigon F, Lesnik P, Rouis M, Chapman J (1991) Discrete subspecies of human low density lipoproteins are heterogeneous in their interaction with the cellular LDL receptor. $\mathrm{J}$ Lipid Res 32: 1741-1753

32. Campos H, Arnold KS, Balestra ME, Innerarity TL, Krauss RM (1996) Differences in receptor binding of LDL subfractions. Arterioscler Thromb Vasc Biol 16: 794-801

33. Aviram M, Lund-Katz S, Phillips MC, Chait A (1988) The influence of the triglyceride content of low density lipoprotein on the interaction of apolipoprotein B-100 with cells. J Biol Chem 263: 16842-16848

34. Henze K, Chait A (1981) Lysosomal enzyme activities and low density lipoprotein receptors in circulating mononuclear cells: effect of insulin therapy in diabetic patients. Diabetologia 20: 625-629
35. Lopes-Virella MF, Klein RL, Virella G (1996) Modification of lipoproteins in diabetes. Diabetes Metab Rev 12: 69-90

36. Lewis GF, Steiner G (1996) Hypertriglyceridemia and its metabolic consequences as a risk factor for atherosclerotic cardiovascular disease in non-insulin-dependent diabetes mellitus. Diabetes Metab Rev 12: 37-56

37. Parthasarathy S, Santanam N (1994) Mechanism of oxidation, antioxydants, and atherosclerosis. Curr Opin Lipidol 5: $371-375$

38. Hunt JV (1997) Glyco-oxidation of LDL: a biochemist's perspective. In: Colaco C (ed.) The glycation hypothesis of atherosclerosis. Eds London Bioscience, Austin, pp 109-126

39. Klein RL, Lyons TJ, Lopes-Virella MF (1990) Metabolism of very low and low-density lipoproteins isolated from normolipidaemic type 2 (non-insulin-dependent) diabetic patients by human monocyte-derived macrophages. Diabetologia 33: 299-305

40. Klein RL, Laimins M, Lopes-Virella MF (1995) Isolation, characterization and metabolism of the glycated and non glycated subfractions of low density lipoproteins isolated from type 1 diabetic patients and non-diabetic subjects. Diabetes 44: 1093-1098

41. Girona J, La Ville AE, Solà R, Plana N, Masana L (1999) Simvastatin decreases aldehyde production derived from lipoprotein oxidation. Am J Cardiol 83: 846-851

42. Deegan P, Owens D, Collins P, Johnson A, Tomkin GH (1999) Association between low-density lipoprotein composition and its metabolism in non-insulin-dependent diabetes mellitus. Metabolism 48: 118-124 